Original

\title{
Comparison of regenerated bamboo and cotton performance in warm environment
}

\author{
Karina Solorio-Ferrales, Carlos Villa-Angulo*, Rafael Villa-Angulo, José Ramón Villa-Angulo \\ Universidad Autónoma de Baja California, Instituto de Ingeniería, Av. De la Normal s/n Col. Insurgentes, C.P. 21280 Mexicali Baja California, Mexico
}

Received 17 September 2016; accepted 2 February 2017

Available online 3 May 2017

\begin{abstract}
Different materials have been used to fabricate summer (warm environment) clothing, such as cotton, nylon, neoprene, polyester and 100\% synthetic fibers. However, because of their mechanical and thermal properties, nylon and polyester cloth has a tendency to rot and chafe in damp conditions. In addition, close-fitting synthetic fibers and neoprene make some wearers feel uncomfortable because of the rapidly occurring body skin sweat. However, bamboo and cotton have demonstrated to have low thermal conductivity. Hence, they are excellent materials to fabricate summer clothing. In this study, a theoretical analysis complemented with practical measurements of thermal properties of three different rib knitted structures produced from a 30 tex yarn of three blends of fibers (100\% regenerated bamboo, 100\% cotton and 50:50 regenerated bamboo: cotton) was realized to compare bamboo and cotton performance in warm environment. Obtained results show that garment thickness and heat storage rate in the human body can significantly be reduced by using $100 \%$ regenerated bamboo, without compromising comfort.

(C) 2017 Universidad Nacional Autónoma de México, Centro de Ciencias Aplicadas y Desarrollo Tecnológico. This is an open access article under the CC BY-NC-ND license (http://creativecommons.org/licenses/by-nc-nd/4.0/).
\end{abstract}

Keywords: Warm environment clothing; Protective materials; Bamboo garment; Modeling behavior

\section{Introduction}

To maintain its temperature in a safety interval, the human body needs to eliminate excessive warmth. To eliminate the excessive warmth, it changes the amount of blood circulating through the body and it increases the amount of liquid transpiration on the body skin. These actions are commonly self-activated once its average internal temperature overpasses the $98.6^{\circ} \mathrm{F}$ $\left(37^{\circ} \mathrm{C}\right)$ (Jessen, 2012; Hockey \& Rew, 1996). Also, when the environmental temperature is close to the temperature of the body skin, the internal temperature regulation becomes more difficult. If the air temperature is equal to or higher than the temperature of the body skin, the blood that circulates close to the body skin cannot help to decrease the human body temperature (Widmaier, Raff, \& Strang, 2013). In addition, if the environmental humidity increases, the evaporation of the liquid transpiration on the body skin decreases. Hence the effort

\footnotetext{
* Corresponding author.

E-mail address: villac@uabc.edu.mx (C. Villa-Angulo).

Peer Review under the responsibility of Universidad Nacional Autónoma de México.
}

of the body to maintain a safety temperature is affected, excessive blood arrives to the body skin and less arrives to the active muscles, the brain, and the other internal organs (Marieb \& Hoehn, 2012). As a consequence, the body capacity to work decreases and a premature exhaustion due to the heat stress is experienced.

The previously described conditions are commonly found in seaside cities and also in many jobs in industrialized countries (Auliciems \& Szokola, 2007). Different approaches have been used to prevent and minimize the effects of premature exhaustion due to heat stress in hot and warm environment. On the one hand, supplements such as drinks specially designed to replace body fluids and electrolytes have been used. They may be of benefit for workers who have very physically active occupations but they may add unnecessary sugar or salt to the diet (Jones, 1992). On the other hand, protective clothing has been used to reduce the effects of environmental stress factors. The materials used in clothing which has been designed for warm and hot weather must be able to give comfort and durability. It must allow air to circulate freely across the skin, which can help to keep the body cool. In addition, the material needs to resist the sun's rays in order to help delay the onset of sunburn. 
Materials such as cotton, nylon 6, nylon 6.6, neoprene, polyester, and $100 \%$ synthetic fibers have been used for warm and hot environment clothing fabrication. However, pure nylon and polyester cloth have a tendency to rot and chafe in damp conditions. In addition, even a close-fitting and lightweight garment made of $100 \%$ synthetic fiber and neoprene make some wearer feel uncomfortable because of the rapidity of body skin sweat. On the other hand, cotton and bamboo are a tribe of flowering perennial evergreen plants in the grass family Poaceae (Das \& Chakrabarty, 2008) which is an excellent candidate for warm environment clothing fabrication due to its mechanical and thermal properties (Mounika, Ramaniah, Prasad, Rao, \& Reddy, 2012; Prakash, Ramakrishnan, \& Koushik, 2013; Raimundo \& Figueiredo, 2009).

In this study, the thermal properties of three different rib knitted structures produced from a 30 tex yarn of three blends of fibers (100\% regenerated bamboo, 100\% cotton and 50:50 regenerated bamboo: cotton) were used to compare the performance of regenerated bamboo and cotton in warm environment. Standardized values for metabolic rate, for different physical activities, were used in the calculations. The heat storage rate in the human body $v s$ clothing insulation for the considered yarn blends was calculated. In addition, the relation of clothing thickness and clothing isolation was established. Theoretical results show that the garment thickness as well as the heat storage rate can significantly be reduced in the human body by using $100 \%$ regenerated bamboo, without compromising comfort.

\section{Heat balance and exchange modeling of human body and clothing}

The interaction of heat with a dressed human body can be described from an arbitrary flux of heat impinging with the dressed body. Once the flux of heat is inside the front surface of the dressed body, the behavior of the flux of heat is determined by the rates of storage, production and losses. By conservation of energy, the net heat storage must balance the net production and losses within the unit volume of the dressed body. Using the nomenclature of Table 1, this can be written as: (Bartkevicius, Rackiene, \& Virbalis, 2008; Holmer, 2006)

$S=(M-W)-(R+C+E+K)-\left(C_{r e s}+E_{r e s}\right)$

where $S$ is the heat storage rate, $M$ is the metabolic energy production rate, $W$ is the external mechanical work, and $R, C$ and $E$ are the radiation, convective and evaporative heat loss from the skin, respectively. $K$ is the conduction to the surfaces by direct contact with skin or clothing, $C_{r e s}$ and $E_{r e s}$ are the convective and evaporative heat losses from respiration, respectively. The units of the rate of storage, production and losses are energy per second, which are joules per second $\left(\mathrm{J} \mathrm{s}^{-1}\right)$ or watts (W). It is useful to standardize over persons of different sizes by using units of watts per square meter $\left(\mathrm{W} \mathrm{m}^{-2}\right)$ of the body surface area.

The energy balance components, $M$ and $W$, describe the heat production in the human body. The other components $(R, C, E$, $K, C_{\text {res }}$, and $E_{\text {res }}$ ) describe the heat consumption. Thermal energy
Table 1

Nomenclature used in the theoretical modeling.

\begin{tabular}{|c|c|c|}
\hline$\overline{\frac{A_{r}}{A_{D u}}}$ & $\begin{array}{l}\text { Fraction of skin surface involved } \\
\text { in heat exchange by radiation }\end{array}$ & $\frac{A_{r}}{A_{D u}} \approx 0.77$ n.d. \\
\hline$C$ & Convective heat loss from skin & $\mathrm{W} \mathrm{m}^{-2}$ \\
\hline CORR & $\begin{array}{l}\text { Correction factor to clothing } \\
\text { insulation }\end{array}$ & n.d. \\
\hline$C_{\text {res }}$ & $\begin{array}{l}\text { Convective heat loss from } \\
\text { respiration }\end{array}$ & $\mathrm{W} \mathrm{m}^{-2}$ \\
\hline E & Evaporative heat loss from skin & $\mathrm{W} \mathrm{m}^{-2}$ \\
\hline$E_{P}$ & Emissivity of the human body & $E_{p} \approx 0.97$ n.d. \\
\hline$E_{\text {res }}$ & $\begin{array}{l}\text { Evaporative heat loss from } \\
\text { respiration }\end{array}$ & $\mathrm{W} \mathrm{m}^{-2}$ \\
\hline$F_{c l}$ & $\begin{array}{l}\text { Reduction factor for sensible heat } \\
\text { exchange due to the clothes warm }\end{array}$ & n.d. \\
\hline$f_{c l}$ & Clothing are factor & n.d. \\
\hline$h_{c}$ & $\begin{array}{l}\text { Convective heat transfer } \\
\text { coefficient }\end{array}$ & $\mathrm{W} \mathrm{m}^{-2} \mathrm{C}^{-1}$ \\
\hline$h_{r}$ & $\begin{array}{l}\text { Radioactive heat transfer } \\
\text { coefficient }\end{array}$ & $\mathrm{W} \mathrm{m}^{-2} \mathrm{C}^{-1}$ \\
\hline$I_{c l}$ & Intrinsic insulation of the clothing & clo \\
\hline$i_{m d y n}$ & $\begin{array}{l}\text { Dynamic permeability index for } \\
\text { the clothing }\end{array}$ & n.d. \\
\hline$i_{m s t}$ & $\begin{array}{l}\text { Static permeability index of the } \\
\text { clothing }\end{array}$ & $i_{m s t} \approx 0.38$ n.d. \\
\hline$L_{r}$ & Lewis relation & $L_{r}=1665^{\circ} \mathrm{CkPa}^{-1}$ \\
\hline$M$ & Metabolic rate & $\mathrm{W} \mathrm{m}^{-2}$ \\
\hline$P_{a}$ & $\begin{array}{l}\text { Vapor pressure of the } \\
\text { environment }\end{array}$ & 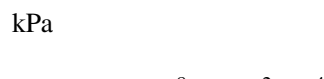 \\
\hline$\sigma$ & Stefan-Boltzmann constant & $\sigma=5.67 \times 10^{-8} \mathrm{~W} \mathrm{~m}^{-2} \mathrm{~K}^{-4}$ \\
\hline$P_{\text {sat }}$ & Saturation vapor pressure & $\mathrm{kPa}$ \\
\hline$P_{s k}$ & $\begin{array}{l}\text { Saturated vapor pressure at mean } \\
\text { skin temperature }\end{array}$ & $\mathrm{kPa}$ \\
\hline$R$ & Radiation heat loss from skin & $\mathrm{W} \mathrm{m}^{-2}$ \\
\hline$R_{a}$ & $\begin{array}{l}\text { Static insulation of boundary air } \\
\text { layer }\end{array}$ & $R_{a} \approx 0.11 \mathrm{~m}^{2}{ }^{\circ} \mathrm{CW}^{-1}$ \\
\hline$R_{\text {etdyn }}$ & $\begin{array}{l}\text { Dynamic total water vapor } \\
\text { resistance of the clothing system }\end{array}$ & $\mathrm{m}^{2} \mathrm{kPaW}^{-1}$ \\
\hline$R H$ & Relative humidity & $(\%)$ \\
\hline$R_{t d y n}$ & $\begin{array}{l}\text { Dynamic thermal resistance of } \\
\text { the clothing system }\end{array}$ & $\mathrm{m}^{2}{ }^{\circ} \mathrm{CW}^{-1}$ \\
\hline$R_{t s t}$ & Static insulation of the clothing & $\mathrm{m}^{2 \circ} \mathrm{CW}^{-1}$ \\
\hline$S$ & Rate of body heat storage & $\mathrm{W} \mathrm{m}^{-2}$ \\
\hline$T_{a}$ & Air temperature & ${ }^{\circ} \mathrm{C}$ \\
\hline$T_{G}$ & Globe temperature & ${ }^{\circ} \mathrm{C}$ \\
\hline$T_{m r t}$ & Mean radiant temperature & ${ }^{\circ} \mathrm{C}$ \\
\hline$T_{S}$ & Dry temperature & ${ }^{\circ} \mathrm{C}$ \\
\hline$T_{s k}$ & Skin temperature & ${ }^{\circ} \mathrm{C}$ \\
\hline$V_{a}$ & Air velocity & $\mathrm{ms}^{-1}$ \\
\hline$W$ & Mechanical power & $\mathrm{W} \mathrm{m}^{-2}$ \\
\hline$W S$ & Walking speed & $\mathrm{ms}^{-1}$ \\
\hline
\end{tabular}

balance is obtained when the heat storage rate is equal to zero $(S=0)$. In addition, when the heat storage rate is positive $(S>0)$ the body temperature increases and there exists a heat gain, hence the body needs to be cooled. On the other hand, when the heat storage rate is negative $(S<0)$ the body temperature decreases and there exists a heat loss, hence the body needs to be heated.

\subsection{Heat production components}

In heat production components, the metabolic rate $M$ is defined as the rate at which the body utilizes food to produce energy. The unit of metabolic rate is the Met, where 
1 Met $=58.15 \mathrm{~W} \mathrm{~m}^{-2}$. An accepted approximation for the calculation of this component is the equation of Harris-Benedict (Horrocks \& Anand, 2000) given by Eq. (2) for males and Eq. (3) for females.

$M=66+13.7 \cdot w+5 \cdot h-6.8 \cdot a$

$M=655+9.6 \cdot w+1.7 \cdot h-4.7 \cdot a$

Here, $w$ is the human weight given in $\mathrm{kg}, h$ is the human height given in meters, and $a$ is the human age given in years. In addition, standardized values for metabolic rates for different physical activities are given by the norm ISO8996 (ISO-8996, 2004). The other heat production component, the external mechanical work $W$ is defined as the realized body mechanical work that does not add internal heat. For most activities it can be made equal to zero.

\subsection{Heat consumption components}

There is a difference in temperature between the environment and the surface of the body with cloth isolation participating in the heat interchange. The radiation heat loss from the skin $R$ is given by Eq. (4)

$R=h_{r} \cdot F_{c l} \cdot\left(T_{s k}-T_{m r t}\right)$

where the mean radiant temperature $T_{m r t}$ is given in ${ }^{\circ} \mathrm{C}$ and its value can be calculated using Eq. (5). The skin temperature $T_{s k}$ is also given in ${ }^{\circ} \mathrm{C}$ and can be calculated using Eq. (6).

$T_{m r t}=T_{G}+1.9 \cdot \sqrt{V_{a}} \cdot\left[T_{G}-T_{s}\right]$

$T_{s k}=35.7-0.0285 \cdot M$

The radioactive heat transfer coefficient $h_{r}$ and the reduction factor for sensible heat exchange due to the clothes $F_{c l}$ are given by Eqs. (7) and (8), respectively.

$h_{r}=\sigma \cdot E_{p} \cdot \frac{A_{r}}{A_{D U}} \cdot \frac{\left[\left(T_{s k}+273\right)^{4}-\left(T_{m r t}+273\right)^{4}\right]}{\left(T_{s k}-T_{m r t}\right)}$

$F_{c l}=\frac{1}{\left(h_{c}+h_{r}\right) \cdot I_{c l} \cdot 0.155+1 / f_{c l}}$

Standardized values for the intrinsic insulation of clothing $I_{c l}$ are given by the norm ISO7730 (ISO-7730, 2005). The clothing area factor $f_{c l}$ which is dependent on $I_{c l}$, and the convective heat transfer coefficient which depends on air velocity $v_{a}$ are given by Eqs. (9) and (10), respectively.

$f_{c l}=1+0.31 \cdot I_{c l}$

$h_{c}=8.7 \cdot\left(v_{a}\right)^{0.6}$

The convective heat loss from the skin can be found using Eq. (11) and it is the heat loss due to air flowing by the skin and carrying away body heat.

$C=\frac{\left(T_{s k}-T_{a}\right)}{R_{t d y n}}$
Here, the ambient temperature $T_{a}$ comes from real measurements and is given in ${ }^{\circ} \mathrm{C}$. The dynamic thermal resistance of the clothing system $R_{t d y n}$ that has units $\mathrm{m}^{2}{ }^{\circ} \mathrm{C} / \mathrm{W}$ is dependent on the characteristics of the clothes worn and on environmental parameters. $R_{t d y n}$ is obtained using Eq. (12).

$R_{t d y n}=R_{t s t} \cdot \operatorname{COR} R$

In Eq. (12) the static isolation of clothing is given by $R_{t s t}=$ $I_{c l} \cdot 0.155+R_{a} / f_{c l}$. The correction factor to clothing insulation $C O R R$ can be calculated using Eq. (13) where the walking speed can be found using $W S=0.0052 \cdot(M-58)$.

$C O R R=e^{\left(0.043-0.398 \cdot V+0.066 \cdot V^{2}-0.378 \cdot W S+0.094 \cdot W S^{2}\right)}$

Evaporative heat loss from the skin to the environment is proportional to the difference between the saturated vapor pressure at mean skin temperature $P_{s k}$ and the vapor pressure of the environment air $P_{a}$. This evaporative heat loss can be found using the next equation

$E=\frac{w \cdot\left(P_{s k}-P_{a}\right)}{R_{\text {etdyn }}}$

In Eq. (14) the skin wittedness is found using $w=0.001 \cdot M$ and the vapor pressure of the environment using $P_{a}=P_{s a t}$. $T_{a} \cdot R H$, where the saturation vapor pressure at a given temperature $P_{\text {sat }}$ is calculated using equation (15) which is known as Antoine's formula. The saturated vapor pressure at mean skin temperature $P_{s k}$ and the dynamic total water vapor resistance of the clothing system $R_{\text {etdyn }}$ are calculated using Eqs. (16) and (17), respectively.

$p_{\text {sat }}=0.1333 \cdot e^{\left(18.6686-\frac{4030.183}{T_{a}+235}\right)}$

$P_{s k}=0.1333 \cdot e^{\left(18.6686-\frac{4030.183}{T_{s k}+235}\right)}$

$R_{\text {etdyn }}=\frac{R_{t d y n}}{L_{r} \cdot i_{m d y n}}$

In Eq. (17) the dynamic permeability index for the clothing is given by $i_{m d y n}=i_{m s t}-6.5 \cdot C O R R+2.6 \cdot C_{O R R^{2}}$. The conduction $K$ is usually very small, relative to other terms, and can safety be neglected.

Heat loss from respiration combines the processes of evaporation of moisture from the lungs as well as convection due to displacement of warm air in the lungs by cold air from the outside environment. Both effects from respiration, convective heat loss $C_{r e s}$ and evaporative heat loss $E_{\text {res }}$, can be quantified using Eqs. (18) and (19) respectively.

$$
\begin{aligned}
& C_{\text {res }}=0.0014 \cdot M\left(34-T_{a}\right) \\
& E_{\text {res }}=0.0173 \cdot M\left(5.87-P_{a}\right)
\end{aligned}
$$

\section{Modeling results}

To compare regenerated bamboo and cotton capacity for warm environment clothing, we used the warm environment characteristics shown in Table 2. These characteristics are found in seaside cities and in many jobs of industrialized countries. Three different rib knitted structures, as shown in Fig. 1, were 
Table 2

Environmental characteristics used in calculations.

\section{Air temperature}

Vapor pressure of the environment

Relative Humidity

Air velocity

Mean radiant temperature

Stefan-Boltzmann constant

Emissivity of the human body

Fraction of skin surface involved in

heat exchange by radiation

Static insulation of boundary air layer

Static permeability index of the clothing

Lewis relation

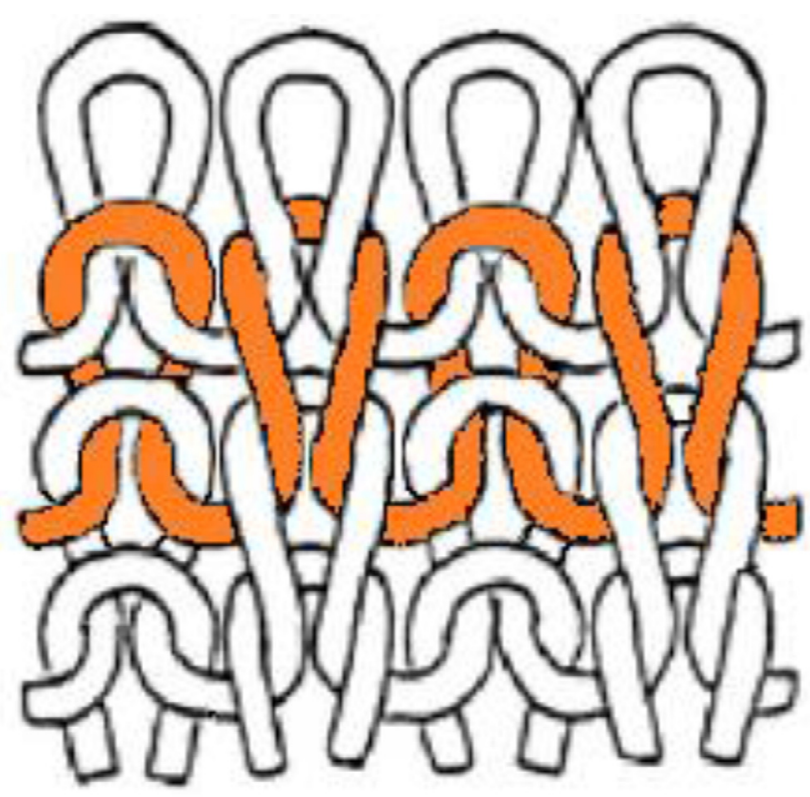

Fig. 1. Rib knitted structure.

produced from a 30 tex yarn of three blends of fibers (100\% regenerated bamboo, $100 \%$ cotton and 50:50\% regenerated bamboo: cotton). The 30 tex yarn of the three blends of fibers were spun in a spinning mill using twist multiplier of 3.8 and 15,500 spindle r.p.m. The regenerated bamboo fibers were produced in a wet-spun process in which natural cellulose was used as raw material in a hydrolysis-alkalization process obtaining a soft mass, from which the natural fibers are mechanically combed out and spun into yarn. The three fabric samples were prepared in a $1 \times 1$ rib machine. The parameters of the knitted machine are: number of feeders 24 , diameter $30 \mathrm{in}$. and machine gauge 18. The hairiness of yarns was measured by Zweigle G566 hairiness tester. For each yarn a cone of $1000 \mathrm{~m}$ length was tested. The number of hairs longer than $3 \mathrm{~mm}$ length per $1000 \mathrm{~m}$ length of yarn was considered for analysis. The thermal conductivities, $\left(\mathrm{W} \mathrm{m} \mathrm{m}^{-1} \mathrm{~K}^{-1}\right.$ ), defined as the property of a material to conduct heat flow, were measured using an Alambeta instrument. Five readings were taken for each of the knitted fabric and then averages were calculated. Table 3 shows the calculated average values for the three fabric samples. The Alambeta
Table 3

Thermal conductivities used in calculations.

\begin{tabular}{ll}
\hline Material & Thermal conductivity $\left(\mathrm{W} \mathrm{m}^{-1} \mathrm{~K}^{-1}\right) \times 10^{-3}$ \\
\hline $100 \%$ cotton & 55.27 \\
100\% regenerated bamboo & 45.04 \\
$50: 50 \%$ reg. bamboo-cotton & 49.66 \\
\hline
\end{tabular}



Fig. 2. Heat storage rates in the human body $v s$ air temperature for four metabolic rates.

instrument uses two measuring heads between which the test sample is placed. Both measuring heads are equipped with heat flow sensors (thermocouples). The lower measuring heads is adjusted to the ambient temperature by suitable cooling means; the upper, heated measuring head is adjusted to a controlled constant differential temperature. The heat flow sensors act up at the contact faces of both measuring heads. When upper measuring head is lowered on the measuring sample the heat flow at the upper surface and the underside of the test sample can be measured. The fabric thickness can also be measured by the instrument. The thermal resistance, $R\left(\mathrm{~m}^{2} \mathrm{~K} \mathrm{~W}^{-1}\right)$, defined as the property of a material to resist a heat flow, was calculated using Eq. (20) (Chidambaram, Govindan, \& Venkatraman, 2012; Majumdar, Mukhopadhyay, \& Yadav, 2010)

$R\left(\mathrm{~m}^{2} \mathrm{~K} \mathrm{~W}^{-1}\right)=\frac{h(\mathrm{~m})}{\left(\mathrm{W} \mathrm{m}^{-1} \mathrm{~K}^{-1}\right)}$

where $h(\mathrm{~m})$ is the garment thickness given in meters. In addition, from the norm ISO8996 (ISO-8996, 2004), we used four standardized values for metabolic rate. The four considered values for metabolic rate and their associated physical activities are: $M=9.2$ met for heavy construction, $M=9$ met for gardening, $M=6.61$ met for medium weight construction and $M=4.46$ met for light weight construction.

Fig. 2, for different ambient temperatures, shows the heat storage rate that needs to be eliminated from the human body to reach thermal energy balance. Thermal energy balance that is given when the heat storage rate in the human body is equal to zero, $(S=0)$, will be referred as thermal comfort in this study. The curves of Fig. 2 were obtained by using Eq. (1) and the parameters given in Tables 1-3. As expected, from Fig. 2 it is observed that as the temperature increases, the heat storage 
Clothing thickness $(\mathrm{mm})$

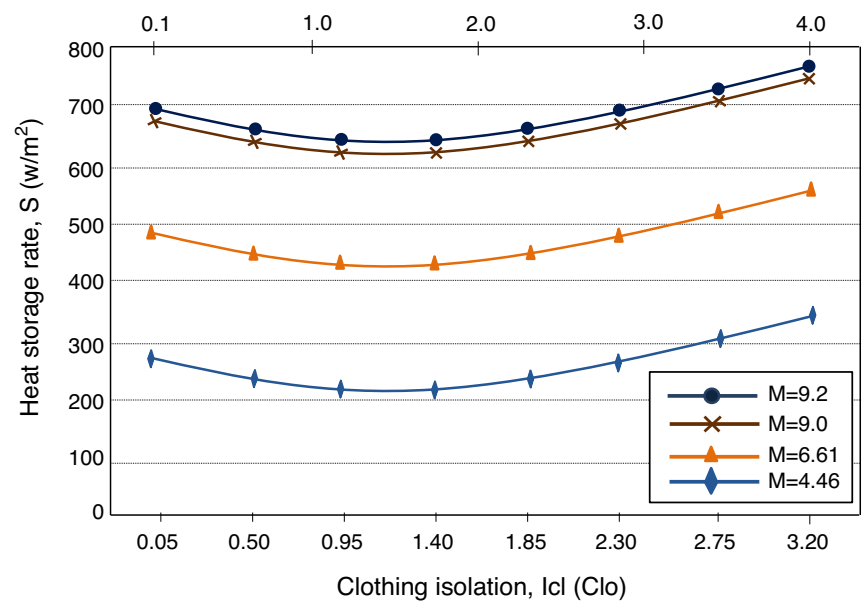

Fig. 3. Heat storage rates in the human body $v s$ clothing insulation for the rib knitted structure fabricated using $100 \%$ regenerated bamboo and four different metabolic rates.

rate in the human body increases, and more heat needs to be eliminated from the body to reach thermal comfort. In addition, as the metabolic rate increases, more heat is stored in the body.

In order to compare the effect in heat storage rate by clothing isolation, the thermal properties of the three fabricated samples were evaluated in the heat balance and exchange models described in Section 2. Fig. 3, for four different metabolic rates, shows the heat storage rate in the human body $v s$ clothing insulation for the rib knitted structure fabricated, using $100 \%$ regenerated bamboo. The curves of Fig. 3 were obtained using Eq. (1) and parameters shown in Tables 2 and 3. From Fig. 3, it is observed that for clothing isolation from 0.05 to $1.4 \mathrm{clo}$, which is given by clothing thickness from 0.1 to $1.18 \mathrm{~mm}$, as the insulation increases less heat is stored in the human body. On the other hand, for clothing isolation greater than 1.4 clo which is given by clothing thickness greater than $1.18 \mathrm{~mm}$, as the insulation increases the heat stored in the human body increases. This behavior is understandable because for clothing thickness less than $1.18 \mathrm{~mm}$ the mechanical and thermal properties of $100 \%$ bamboo allows air to circulate freely across the skin, which helps to keep the body cool. On the other hand, increases in clothing thickness until reaching 3 clo of isolation represents a thick and heavy garment such as winter wear; hence, for characteristics shown in Table 2, the heat storage rate increases. In addition, it is observed that as the metabolic rate decreases less heat is stored in the body. Hence, less heat needs to be eliminated from the body to reach thermal comfort.

Fig. 4 shows the heat storage rate in the human body $v s$ clothing insulation for the rib knitted structure fabricated using $100 \%$ cotton and the considered metabolic rates. In addition, Fig. 4 shows the relation of clothing thickness and clothing isolation. From Fig. 4, it is observed that as the clothing insulation increases from 0.05 to $2.75 \mathrm{clo}$, no significant change on the amount of stored heat in the human body is obtained. However, for clothing isolation greater than 2.75 clo the heat storage rate in the human body starts drastically increasing. Similar to $100 \%$ bamboo, cotton clothing thickness with isolation close to 3 clo

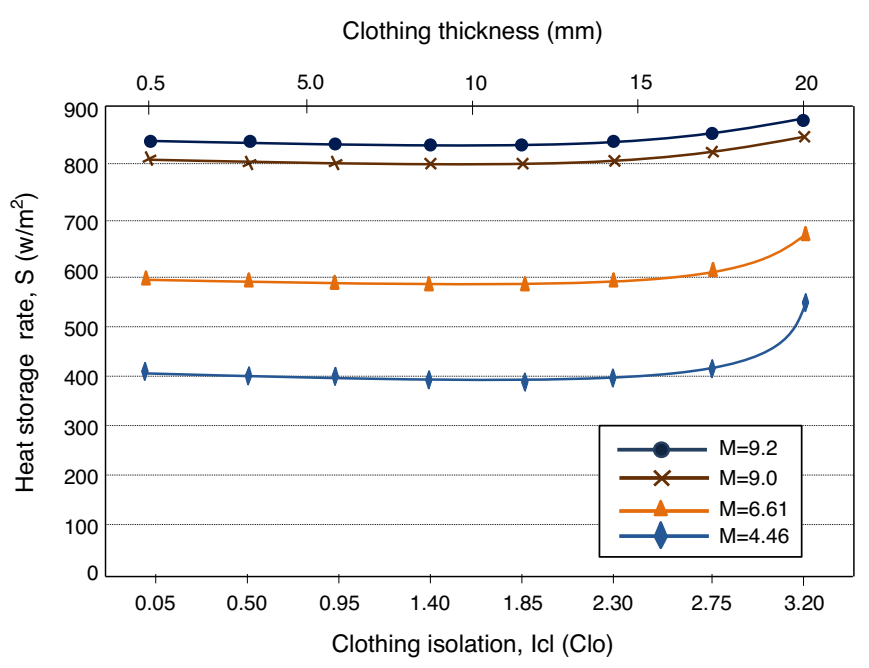

Fig. 4. Heat storage rate in the human body $v s$ clothing insulation for the rib knitted structure fabricated using $100 \%$ cotton and four different metabolic rates.



Fig. 5. Heat storage rate in the human body $v s$ clothing insulation for the rib knitted structure fabricated using 50:50\% regenerated bamboo-cotton and four different metabolic rates.

represents a thick and heavy garment such as winter wear. In addition, it is also observed that as the metabolic rate decreases due to decrease in physical activity, less stored heat needs to be eliminated from the body.

Fig. 5 shows the heat storage rate in the human body vs clothing insulation for the rib knitted structure fabricated using 50:50\% regenerated bamboo-cotton. Fig. 5 also shows the relation of clothing thickness and clothing isolation. Similar to $100 \%$ cotton (Fig. 4), in Fig. 5 it is observed that as the clothing insulation increases from 0.05 to $2.75 \mathrm{clo}$, no significant change on the amount of stored heat in the human body is obtained. However, for clothing isolation greater than $2.75 \mathrm{clo}$, the heat storage rate in the human body starts drastically increasing. The observed difference between 100\% cotton (Fig. 4) and 50:50\% regenerated bamboo-cotton (Fig. 5) is that 50:50\% regenerated bamboo-cotton can reach the same clothing isolation as $100 \%$ cotton with a half of clothing thickness. In addition, it is also 


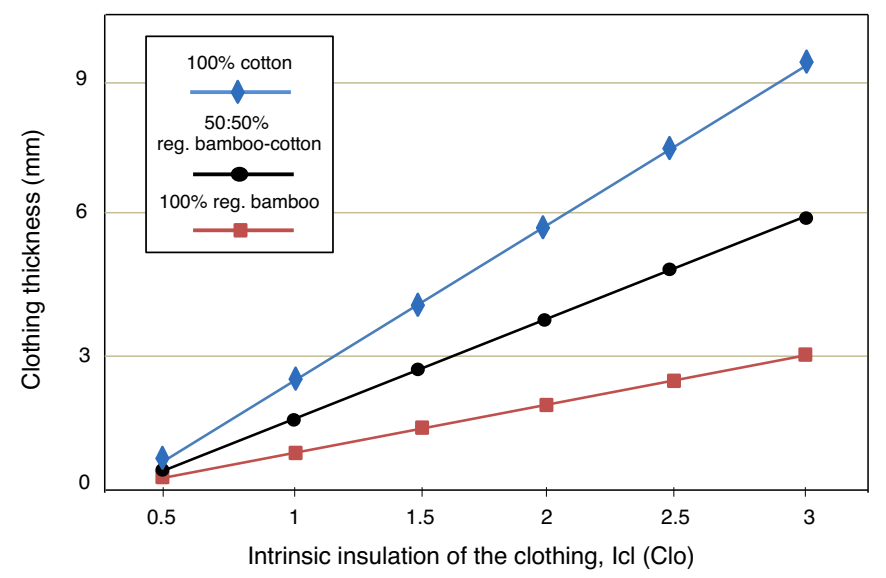

Fig. 6. Clothing thickness vs intrinsic insulation of the clothing for $100 \%$ regenerated bamboo, $100 \%$ cotton and 50:50\% regenerated bamboo-cotton yarn blends.

observed that as the metabolic rate decreases, less stored heat needs to be eliminated from the body.

Fig. 6 shows clothing thickness $v s$ intrinsic insulation of the clothing for $100 \%$ regenerated bamboo, $100 \%$ cotton and 50:50\% regenerated bamboo-cotton yarn blends. As expected, from Fig. 6 it is observed that intrinsic insulation of the clothing increases when clothing thickness is increased. It is seen that $100 \%$ regenerated bamboo can reach isolation values using smaller clothing thickness than 100\% cotton and 50:50\% regenerated bamboo: cotton. For example, 3 clo of isolation can be given by a $100 \%$ regenerated bamboo garment with a thickness of $3 \mathrm{~mm}$, while a garment of $100 \%$ cotton and 50:50\% regenerated bamboo cotton need $5.9 \mathrm{~mm}$ and $9.6 \mathrm{~mm}$ of thickness, respectively. Hence, to reach intrinsic insulation of the clothing of $3 \mathrm{clo}$, the garment thickness needed by using $100 \%$ regenerated bamboo is more than three times smaller as compared to $100 \%$ Cotton, and more than two times smaller as compared to 50:50\% regenerated bamboo: cotton.

\section{Discussions and conclusions}

In this study, thermal properties of a 30 tex yarn from a blends of $100 \%$ fiber of regenerated bamboo, $100 \%$ fiber of cotton and 50:50\% fiber of regenerated bamboo: cotton were used to compare bamboo and cotton performance in warm environment. Four physical activities, characterized by their metabolic rate, were used in the calculations. Theoretical results show that $100 \%$ regenerated bamboo has a better isolation performance in hot environment. The heat storage rate in the human body can significantly be reduced by using $100 \%$ regenerated bamboo. In addition, the garment thickness can also be significantly reduced by using $100 \%$ regenerated bamboo. This means that 3 clo of thermal isolation can be given by a garment of $100 \%$ regenerated bamboo with a thickness of $3 \mathrm{~mm}$, while $5.9 \mathrm{~mm}$ and $9.6 \mathrm{~mm}$ of thickness are needed by 50:50\% regenerated bamboo: cotton and $100 \%$ cotton, respectively. In summary, theoretical analysis, complemented with practical measurement of thermal properties of three different rib knitted structures produced from a 30 tex yarn of three blends of fibers, show that $100 \%$ regenerated bamboo can be used to reduce garment thickness and heat storage in warm environment clothing, without compromising comfort. Hence, a comprehensive understanding of theoretical models, will be of great importance to experimentalists, who are potentially interested in obtaining the numerical estimates and correlate the theoretical results with practical measurements.

\section{Conflict of interest}

The authors have no conflicts of interest to declare.

\section{References}

Auliciems, A., \& Szokola, S. V. (2007). Thermal comfort (2nd ed.). Brisbane: Passive and Low Energy Architecture International and Department of Architecture, University of Queensland.

Bartkevicius, S., Rackiene, R., \& Virbalis, J. A. (2008). Analysis of the energy balance in the system human-clothing-environment. Electronics and Electrical Engineering, 61-64.

Chidambaram, P., Govindan, R., \& Venkatraman, K. C. (2012). Study of thermal comfort properties of cotton/regenerated bamboo knitted fabrics. African Journal of Basic \& Applied Sciences, 4, 60-66.

Das, M., \& Chakrabarty, D. (2008). Thermogravimetric analysis and weathering study by water immersion of alkali treated bamboo fibres. BioResources, 3, 1051-1062.

Hockey, S. M., \& Rew, P. J. (1996). Review of human response to thermal radiation. HSE contract research report (Vol. 97) HSE.

Holmer, I. (2006). Protective clothing in hot environments. Industrial Health, 44, 404-413.

Horrocks, A. R., \& Anand, S. C. (2000). Handbook of technical textiles. Cambridge: Woodhead Publishing, The Textile Institute.

ISO-8996. (2004). Ergonomics - Determination of metabolic heat productions. Geneva: ISO.

ISO-7730. (2005). Ergonomics of the thermal environment. Geneva: ISO.

Jessen, C. (2012). Temperature regulation in humans and other mammals. New York: Springer Science \& Business Media.

Jones, E. F. (1992). Evaporation of water with emphasis on application and measurements. pp. 25-43. Michigan: Lewis Publishers.

Majumdar, A., Mukhopadhyay, S., \& Yadav, R. (2010). Thermal properties of knitted fabrics made from cotton and regenerated bamboo cellulosic fibres. International Journal of Thermal Sciences, 49, 2042-2048.

Marieb, E. N., \& Hoehn, K. (2012). Human anatomy \& physiology (9th ed.) Pearson Education.

Mounika, M., Ramaniah, K., Prasad, A. R., Rao, K. M., \& Reddy, K. H. C. (2012). Thermal conductivity characterization of bamboo fiber reinforced polyester composite. Journal of Materials and Environmental Science, 3, 1109-1116.

Prakash, C., Ramakrishnan, G., \& Koushik, C. V. (2013). A study of the thermal properties of bamboo knitted fabrics. Journal of Thermal Analysis and Calorimetry, 111, 101-105.

Raimundo, A. M., \& Figueiredo, A. R. (2009). Personal protective clothing and safety of firefighters near a high intensity fire front. Fire Safety Journal, 44, 514-521.

Widmaier, E. P., Raff, H., \& Strang, K. T. (2013). Vander's human physiology: The mechanisms of body function. Kindle Edition. 